\title{
Instituting a Summer Supplemental Instruction Program
}

\author{
David Marling and Barbara Bradford
}

Supplemental instruction, a peer facilitated retention program, was introduced at the University of North Texas in the summer of 1999. Several class sections, in which at least one third of the class traditionally receive "Ds," " $F s$," or "Ws" (withdrawal from the class), were targeted for this pilot program. These courses included college algebra, general chemistry, animal biology and American government. The results indicated that $83 \%$ of the students attending supplemental instruction received a grade of " $C$ " or better. Conversely, only $64 \%$ of those who did not attend received better than a " $C$." In addition, of the 44 students who withdrew from these classes, only $11 \%$ (five students) were supplemental instruction participants. These findings indicate that supplemental instruction is a valid retention program at the University of North Texas.

Retention has been a critical issue on college campuses since the 1980's (Cowart, 1987). Every university devotes significant resources to determine options which ensure that their students remain enrolled and on schedule to graduate. Retention specialists have focused in great detail on issues such as campus climate, the unique needs of at-risk students, and enrollment strategies. One of the newer strategies for retention success is supplemental instruction (SI).

Whereas many intervention programs focus on students having academic difficulty, SI targets difficult classes; i.e., classes with at least a thirty percent "D," "F," or "W" rate, and provides outside assistance for the students in those classes. SI leaders, selected from students who have previously passed these classes with an "A," have an instructor's approval, and are perceived as able to engage students in the academic process. These leaders retake the course and conduct study sessions outside of class with students from that section. The SI leader holds approximately fifteen sessions during a summer semester, with each session lasting one to two hours.

The purposes of SI sessions are to help students with their notetaking, homework preparations, and test taking skills. The sessions are free of charge and designed to be a non-threatening way to receive academic assistance since the SI leader does not participate in the students' evaluations. Additional benefits of the program include: (a) it is a proven method of increasing retention rates; (b) it is cost effective since the retention of only one student will cover the cost of a course for the semester; (c) it incorporates study skills into specific content areas, and these skills should transfer to other courses; (d) it facilitates the learning of critical thinking skills as modeled by the SI leader; and (e) it is a way for students to connect with other students and to form social bonds in an academic setting.

Supplemental instruction is introduced into a class only with prior approval of the

David Marling is Coordinator of the Learning Center marling@dsa.admin.unt.edu and Barbara Bradford is Director of the Learning Center at the University of North Texas. bradford@dsa.admin.unt.edu 
instructor since the relationship between the SI leader and the instructor is crucial to the success of the program. The leader relies on the instructor to provide information that allows the leader to focus on important aspects of the class. The instructor also examines practice tests constructed by the SI leader to ensure that the content adequately covers the course material. Once a positive relationship is established with several instructors, the program becomes much easier to introduce into other sections of the course.

The ultimate purpose of the SI program is to integrate reading and study skills with course content, thus teaching skills transferable to future classes. The SI leaders are trained to assist the students while encouraging them to work independently. One of the key concepts of supplemental instruction is that students learn critical thinking skills. Many students struggle to adjust to the different ways in which knowledge is applied in high school and in college. The transition from tests based on memorization in high school to tests that require comprehension and analysis in college creates problems for many freshmen. SI helps students gain confidence in their abilities to apply the knowledge in ways that will satisfy the course requirements.

The data shows that SI significantly increases the chances for students to succeed in the course. Supplemental instruction students make higher grades, drop the course at a much lower rate than non-SI students, and seldom fail the class (Martin and Arendale, 1994). In addition, SI draws participation from a high percentage of students in SI sections and is well-received by those who attend. Also, students who initially fail the course and are re-taking it greatly benefit from the sessions, while those who choose not to attend generally do not better their performance. Overall, the program achieves excellent results while supporting the instructors' curriculum.

Supplemental Instruction sessions draws students from a wide variety of demographics and ability ranging from freshmen to non-traditional students who are returning to college. One key point of the program is that it is not remedial in nature. Some students attend in order to solidify an 'A', while others are trying to pass the class for the third time. The diversity of students is conducive to group activities that allow the different types of students to work together to solve problems. The only criterion for participating in SI is that the student must be enrolled in a class section for which an SI leader has been assigned.

\section{Method}

The University of North Texas (UNT), a large metropolitan university with an enrollment of approximately 26,500 students, conducted a pilot study in supplemental instruction during summer 1999. During the first session of summer, the program provided services for five sections (two sections of college algebra and one section each of American government, animal biology, and general chemistry) with one SI leader per section. During the second session, four leaders were assigned to three sections of college algebra and one section of Texas government. In each of these courses, at least one-third of the students made a "D," "F," or "W" during the spring 1999 semester.

At each session, the leaders distributed sign-in sheets to record attendance. These records were reviewed at the end of each semester to determine how many times each 
student attended a session. Students who attended more than one session were counted as having participated in the SI program.

\section{Results}

The following charts illustrate the SI Group (students who attended sessions), non-SI Group (students who did not attend sessions), and the total number of students enrolled in each class. Table 1 and Table 2 depict the results from each summer session and Table 3 presents the combined results of the pilot program.

TABLE 1

\section{First Session Results}

$$
\text { SI Group }(\mathrm{N}=102) \quad \text { Non-SI Group }(\mathrm{N}=168) \quad \text { Total }(\mathrm{N}=270)
$$

\begin{tabular}{ccccccc} 
Grade & Number & Percent & Number & Percent & Number & Percent \\
\hline A & 30 & $29 \%$ & 31 & $18 \%$ & 61 & $22 \%$ \\
\hline B & 35 & $34 \%$ & 40 & $24 \%$ & 75 & $28 \%$ \\
\hline C & 23 & $23 \%$ & 39 & $23 \%$ & 62 & $23 \%$ \\
\hline D & 6 & $6 \%$ & 21 & $13 \%$ & 27 & $10 \%$ \\
\hline F & 5 & $5 \%$ & 14 & $8 \%$ & 19 & $7 \%$ \\
\hline $\begin{array}{c}\text { W } \\
\text { A, B, C }\end{array}$ & 3 & $2 \%$ & 23 & $14 \%$ & 26 & $10 \%$ \\
\hline $\begin{array}{c}\text { Combined } \\
\text { D, F, W }\end{array}$ & 14 & $14 \%$ & 58 & $35 \%$ & 72 & $27 \%$ \\
\hline $\begin{array}{c}\text { Grade Pt. } \\
\text { Average }\end{array}$ & 2.79 & & 2.36 & & 2.54 & \\
\hline
\end{tabular}

It is clear that SI students achieved better grades than their non-SI counterparts. The GPA differential between SI and non-SI students was nearly one-half of a letter grade (.41). The most telling statistic, however, is that $86 \%$ of the SI group made at least a "C" in the class, exceeding the non-SI group by more than $20 \%$. Also, only three SI participants withdrew from the class, while twenty-three non-SI students withdrew.

Another important set of data in assessing the program is the number of students attending the sessions and the number of sessions each participating student attended. Thirty-nine percent of all students enrolled in SI classes attended more than one SI 
session. The mean number of students attending each session was 6.59 , with the average SI participant attending 4.7 sessions. In addition, supplemental instruction received a satisfaction rating from students of 4.22 on a one to five point Likert Scale.

\section{TABLE 2}

\section{Second Session Results}

SI Group (N=88) Non-SI Group $(\mathrm{N}=104) \quad$ Total $(\mathrm{N}=192)$

\begin{tabular}{ccccccc} 
Grade & Number & Percent & Number & Percent & Number & Percent \\
\hline A & 10 & $11 \%$ & 17 & $16 \%$ & 27 & $14 \%$ \\
\hline B & 36 & $41 \%$ & 24 & $23 \%$ & 60 & $31 \%$ \\
\hline C & 24 & $27 \%$ & 23 & $22 \%$ & 47 & $24 \%$ \\
\hline D & 10 & $11 \%$ & 15 & $14 \%$ & 24 & $13 \%$ \\
\hline W & 6 & $7 \%$ & 9 & $9 \%$ & 15 & $8 \%$ \\
\hline $\begin{array}{c}\text { Combined } \\
\text { A, B, C }\end{array}$ & 2 & $2 \%$ & 16 & $15 \%$ & 18 & $9 \%$ \\
\hline $\begin{array}{c}\text { Combined } \\
\text { D, F, W }\end{array}$ & 18 & $80 \%$ & 64 & $61 \%$ & 134 & $69 \%$ \\
\hline $\begin{array}{c}\text { Grade Pt. } \\
\text { Average }\end{array}$ & 2.40 & $20 \%$ & 40 & $39 \%$ & 58 & $31 \%$ \\
\hline
\end{tabular}

The results from the second summer semester are consistent with the findings of the first session. The SI group made a "C" or above approximately $20 \%$ more often than the non-SI group. In addition, only two SI students withdrew, while sixteen non-SI students dropped the course. The GPA differential in the second session was less than the GPA differential of the second session due to an abnormally high achievement rate in one class. Because a low percentage (19\%) of the students from that class attended SI sessions, the overall non-SI numbers drastically increased.

During the first summer session, there was also an increase in attendance. Forty-five percent of students enrolled in SI sessions attended more than one session. The mean number of sessions attending was four, while the mean size of each session was 6.6 students. Finally, SI received a satisfaction rating from students of 4.4 on a five point Likert Scale. 


\section{Overall Results}

SI Group $(\mathrm{N}=190) \quad$ Non-SI Group $(\mathrm{N}=272) \quad$ Total $(\mathrm{N}=462)$

\begin{tabular}{cccccccc} 
Grade & Number & Percent & Number & Percent & Number & Percent \\
\hline A & 40 & $21 \%$ & 48 & $18 \%$ & 88 & $19 \%$ \\
\hline B & 71 & $37 \%$ & 64 & $23 \%$ & 135 & $29 \%$ \\
\hline C & 47 & $25 \%$ & 62 & $23 \%$ & 109 & $23 \%$ \\
\hline D & 16 & $8 \%$ & 36 & $13 \%$ & 36 & $52 \%$ \\
\hline F & 11 & $6 \%$ & 25 & $9 \%$ & 36 & $8 \%$ \\
\hline $\begin{array}{c}\text { Combined } \\
\text { A, B, C }\end{array}$ & 158 & $83 \%$ & 172 & $64 \%$ & 330 & $71 \%$ \\
\hline $\begin{array}{c}\text { Combined } \\
\text { D, F, W }\end{array}$ & 32 & $17 \%$ & 100 & $37 \%$ & 132 & $27 \%$ \\
\hline $\begin{array}{c}\text { Grade Pt. } \\
\text { Average }\end{array}$ & 2.60 & & 2.33 & & 2.45 & \\
\hline
\end{tabular}

\section{Summary and Conclusion}

The pilot program was much more successful than originally envisioned. Lack of attendance had been an early concern since students have busy summer schedules. However, students did attend, and their grades did improve.

National data indicates that students attending SI receive a half to a whole letter grade better than non-SI students (Martin and Arendale, 1994). The program at UNT achieved that mark. In addition, $86 \%$ of SI students made a " $C$ " or better in their classes, and there were much higher percentages of "A" and "B" students as well which indicates that SI did contribute to higher letter grades. There were also fewer "D" students in SI compared to non-SI, which appears to support the theory that students get an extra "boost" from SI sessions, enabling them to get a "C" or better.

Finally, and most importantly, students who attended SI sessions dropped or withdrew from the class at a much lower rate than non-SI students. Twenty-three of the twenty-six students who withdrew from class did not attend SI sessions. In addition, the students who were retaking college algebra in the four sections in which SI was offered frequently utilized the program. In five sections of math, 134 of the students on the original class rosters were retaking the class. Thirty-nine of those individuals came to 
SI, and thirty-one passed. Of the ninety-five who did not attend SI, only twenty-three passed the course. Thus, $79 \%$ of the SI students who were retaking the class passed, while only $24 \%$ of non-SI students retaking the course passed. Again, this seems to indicate that SI is giving the students the necessary confidence and encouragement to remain in the course, improve their grades, and stay in school.

Supplemental instruction has proven that it can be an excellent tool in helping and retaining students at the University of North Texas. Students achieve higher grades, form personal bonds, and accumulate skills transferable to other classes. The program has been expanded for fall 1999 classes and, as more students become familiar with SI and increase their requests for SI courses, the program should continue to expand. Although supplemental instruction has very specific parameters that limit its usability to a limited number of courses, its benefits for students and effects on retention make it a valuable asset in combating student attrition.

\section{References}

Cowart, Susan Cooper. (1987). What Works in Student Retention in State Colleges and Universities.

Martin, D., and Arendale, D. (1994). New Directions for Teaching and Learning; 02710633; no. 60 Jossey-Bass Higher and Adult Education Series. San Francisco: JosseyBass Publishers. 